\title{
I Can't Breathe: How Digital Video Becomes an Emancipatory Technology
}

\author{
Jordana George \\ Texas A\&M University \\ jgeorge@mays.tamu.edu
}

\author{
Thomas George \\ Texas A\&M University \\ Thomas.George@tamu.edu
}

\author{
René Moquin \\ Northeastern State University \\ Moquin@nsuok.edu
}

\begin{abstract}
This grounded theory study explores how bystander digital video distributed via social media documents perceived injustice and serves as an emancipatory technology. Using 30 examples, the study provides insight into how bystander videos impact perceived social injustice with potential visual evidence and how bystander videos ultimately shape larger social movements. We find that potential evidentiary video events break down into eight theoretical areas: instigation, target, place, perceived injustice, tools, witness, potential evidence, and outcomes. We find that while bystander video spread through social media can indeed serve as an emancipatory technology with substantial positive outcomes, care must be taken to avoid oversaturation that could result in desensitization and lower efficacy.
\end{abstract}

\subsection{Introduction}

On February 26th, 2013, in the South African township of Daveyton, a Mozambican immigrant lost his life in one of the most severe cases of police misconduct, brutality, and abuse in years. Police beat Mido Macia in front of a crowd of bystanders. He was then handcuffed to the back of a police van and dragged down the road. The entire incident was captured on video by a bystander and quickly circulated, causing widespread outrage. Macia died in a jail cell from massive trauma resulting in hypoxia just hours later. Because of the bystander video, eight of the officers involved in the incident were tried and found guilty in Macia's murder. The court sentenced each officer to 15 years in prison. Macia's crime, for which the police saw this treatment as a fitting punishment, for was illegally parking his taxi [36].

For the past decade, we have witnessed a rise in videos produced and distributed by individuals, aided by cell phones with excellent camera features, easy to use repositories, such as YouTube, and fast dissemination through social media platforms. Filming incidents of perceived injustice has become so ubiquitous that cell service sometimes fails during protests because of so many people uploading video [38]. Citizen generated video documentation of civil disobedience, political violence, and police brutality has become a regular occurrence [5].

Using images as potential evidence is not new, having been used in the criminal justice system for decades [30]. One of the earliest examples of amateur video used as potential evidence of perceived injustice and inciting social action is the Rodney King incident [38]. The case occurred in Los Angeles in 1991 when a bystander at a nearby apartment filmed a Black man being beaten by police [20]. The evidentiary nature of bystander videos was quickly recognized by social organizers as an emancipatory technology [15]. We define emancipatory technologies as those that can be used to improve outcomes such as social or financial emancipation [23, 26]. As enthusiastic as the 1990s activists were about emancipatory technology, the lack of distribution networks, video skills, and equipment created a significant barrier.

The introduction of video-capable smartphones and the emergence of social media democratized video creation and content distribution [20]. It changed again with the advent of cloud-based surveillance such as Ring doorbells and personal dashboard-mounted cameras in vehicles 
(dashcams). Video activism thrives today around the world, documenting everything from grocery store bullies to road rage to public hangings of political dissenters [16]. Video activism is an integral part of digital activism. As such, our research asks:

How do bystander digital videos that are spread through social media impact perceived social injustice?

What are the elements that make up this phenomenon?

The goals of this study are to provide a foundation on video activism and emancipatory technologies, touch base on skeptics of potential video evidence, and explain our findings through the lens of critical theory. We follow with our methodology, explain our data and collection process, and present our analysis and results. We then offer a discussion and a look at the implications of our findings.

\subsection{Literature and Background}

To inform ourselves on the various aspects of cellphone videos, we delved into the literature on video activism and emancipatory technologies. We also examined work on why people are skeptical of potential evidence of perceived injustice to understand why such technologies might not achieve their goal. Last, we discuss critical theory, which we use as our lens.

\subsection{Video activism}

Digital activism, defined as "digitally mediated social activism" [19], takes a range of forms from sharing a political post on social media to protesting in a capitol thousands of miles from home. A prevalent form of digital activism in the past decade is video activism. We define video activism as the use of video technologies to document perceived injustice, inform the public, and influence elites [4]. There are two aspects of video activism: creation and dissemination [42]. Filmmakers include random bystanders who record and upload impromptu content to social media sites within minutes of an event, as well as skilled political organizers with professional video editing skills [5]. There is even a subgroup of video activists known as cop watchers, who follow police in hopes of catching perceived injustice on film [16]. Devices commonly used for videos include cellphones, dashboard cameras (dashcams), and cloudbased surveillance such as Ring doorbells and closed-circuit television (CCTV), as well as police-worn body cameras (bodycam).

Video dissemination is typically accomplished through social media platforms such as Facebook and Twitter, or a digital media storage platform such as YouTube [22]. Video content creation and dissemination provides:

- Potential evidence of perceived injustice [30].

- A frame for sharing perceived injustice events in context [43].

- Repository sites that have a place for mourning and commemoration [5].

Images are a useful tool in social frames. Framing is generally thought of as words (spoken or written) that provide meaning [43]. Framing often includes certain vocabularies or mental shortcuts to understanding $[7,15]$. Videos take framing a step further by providing powerful experiential messages enabling viewers to embed visual mental frames. Videos are particularly strong tools for activism because images have "emotional stickiness" [16, 28]. This means that images have a greater impact than text or audio alone and the picture sticks with the viewer for longer periods of time. Videos can also combine multiple sources of media and images into powerful collages, as the "victim's data double becomes more human than human" [30]. Framing is also critical because the filmmaker's perspective colors their perception and representation of events.

Raw videos tend to engender empathy for whoever embodies that view, whether it is a Police bodycam or a phone held by a victim. Research shows that people consider police actions less intentional and more justified when police bodycams document a situation [24]. The same can be said for videos filmed from the victim's perspective.

Empathy for victims is expressed in another side of video activism; its function as a memorial for the fallen. YouTube and other sites allow comments where friends, 
family, and well-wishers can support each other [5].

Bystander videos are not, however, universally accepted, especially by elites and agencies that are often targeted, such as the police. Some in these fields believe that bystander videos do not provide a fair and objective account because of the filmmaker's perspective and framing and the public perception based on a viral social media post $[14,35]$.

A downside to video activism is overexposure, which can lead to desensitization [41]. When people are desensitized to perceived injustice, they are less likely to work toward emancipation [32]. Little of the extant literature on video activism delves into this aspect.

\subsection{Emancipatory technologies}

Emancipatory technology in Information Systems (IS) research tends to be segregated into subfields, such as organizational (firm) [23, 28], financial/economic [18], societal (the marginalized and disadvantaged) [25, 26] and pedagogical [44]. In this study, we focus on societal emancipation through technology.

Marginalized people use emancipatory technologies for social goals mainly by proliferating frames, exposing the truth, and pushing social change [3, 29]. Such activities may include education, proselytizing, and organizing [19].

Some technologies are polarizing, providing emancipatory affordances in one setting and hegemonic in another [29]. Some technologies exploit the communicative properties of social media. Facebook and Twitter are frequently used to share activist videos, but such endeavors would not be condoned in more restrictive countries and could land a person in prison or worse. Thus, we see that not all technology is emancipatory, and even the same technology may or may not be emancipatory depending on context and could be hegemonic through elite control of the message or access to the technology [29].

\subsection{Skeptics}

Last, we examine an individual's proscription when exposed to video activism. The syllogism "seeing is believing" used to be considered accurate. However, the last decade has seen a significant rise in public skepticism due to the proliferation of fake news [31,33]. We categorize skeptics into psychological and technology subfactors.

Much of the research on disbelief, especially around fake news, and conspiracy theories, focuses on confirmation bias. Confirmation bias refers to the tendency for people to believe things that agree with their worldview [33, 37]. However, we suggest that cognitive bias, the tendency to be skeptical of something that disagrees with one's worldview, is equally important in this context [4]. When presented with potential video evidence that disagrees with an individual's epistemic stance, it can cause cognitive dissonance. Treating the potential evidence as false reduces that tension and is accomplished through recognition of the video's framing. While frames are helpful for sympathizers, they are also catalyzers for opponents.

In addition, skeptics may not be in an "all or nothing" mindset. These skeptics may be waiting for more information or further clarification on the full interaction before deciding on their stance, and not rely on the window of the encounter caught on camera.

Another justification for skeptics to disqualify video is the existence of "deepfakes." Deepfakes are videos that use artificial intelligence (AI) to create highly realistic scenes [39]. Today, even amateurs can create AI videos easily through online tools that start at $\$ 30$ a month [45].

Now that we have set the stage for understanding video activism, emancipatory technologies, and skeptics, we discuss our choice of critical theory for our theoretical foundation.

\subsection{Theoretical lens: critical view}

We employ critical theory in this paper, an approach that attempts to tackle the causes of perceived injustice through remedy and change [34]. Theories do not change the world. Theories are our lens for 
viewing the world. By changing our lens, we can improve our worldview [2]. We include three aspects of critical theory in this study: insight, critique, and transformative redefinition [2, 34]. Insight refers to new perspectives. Critique looks deeper into society to understand how and why perceived injustice exists. Transformative redefinition is prescriptive and offers remedies to society. We draw from Habermas' theory of communicative action. While Foucault and Bourdieu also provide critical perspectives $[8,9,13]$, we felt that Habermas' work on communicative action better reflected the phenomenon of digital videos as an emancipatory technology [26]. The theory of communicative action describes how the structure of modern life, including government, economies, and legal systems, impede and damage communities by disrupting people's communications. Habermas seeks a new world distinguished by free and open communication [21].

Habermas notes that communities and institutions have become uncoupled and that is where problems begin. If institutions and communities (or system and lifeworld in Habermas' terms) can be rejoined, while each retaining its strengths, they can enhance societal existence. This might start as an improved standard of living and could grow into emancipation from war or environmental destruction. Critical aspects of communicative action include the following: intentions are communicated truthfully and accurately; organized action is coordinated and planned based on a group's values and beliefs; and people are judged based on their actions and impact. Last, methods of communicative action include a shared form of communication. Distortion of the message occurs when the Speaker's message is inaccurate or invalid. Long term distortion of messages damages credibility [21].

\subsection{Method}

This study uses grounded theory methodology (GTM) to examine a collection of 30 incidents of bystander video content disseminated on social media. We chose GTM because it is useful for developing inductive theory [27] and also because GTM is commonly used in IS research for exploring socio-technical behavior in new research areas [40]. Given the gritty nature of video-captured perceived injustice, including all manner of violence, we also believe that GTM provides a means to bring out the realism of the subject. The dataset for this study was built using Google search and keywords (listed in Table 1).

Table 1. Keywords for search

\begin{tabular}{|l|l|}
\hline $\begin{array}{l}\text { Filmed police } \\
\text { brutality }\end{array}$ & $\begin{array}{l}\text { Police } \\
\text { accountability }\end{array}$ \\
\hline $\begin{array}{l}\text { Inverse } \\
\text { surveillance }\end{array}$ & Police misconduct \\
\hline Cop watch & Viral video \\
\hline List of riots & $\begin{array}{l}\text { Potential video } \\
\text { evidence }\end{array}$ \\
\hline I can't breathe & $\begin{array}{l}\text { List of killings by } \\
\text { law enforcement by } \\
\text { country }\end{array}$ \\
\hline
\end{tabular}

We also searched Wikipedia with the keywords using backward search from the articles' references. Finally, we included an open dataset called "GeorgeFloyd Protest police brutality videos on Twitter" [12]. Our inclusion criteria consisted of 1) Bystander/citizen ad hoc or surveillance video (excluding police body cams, planned/organized video, or other institutional videos), 2) Video sources included cellphones, personal surveillance such as cloud-based video doorbells, and personal dashcams, and 3) Use of social media for dissemination of the video.

The data was organized as follows: Cases were entered and categorized in a shared Google spreadsheet. Each case included the following fields: Incident, Date, Summary, Outcomes, Actors, SM Platform, Video Length, Demographics, Location, Notes, URL, and Source. While the number of SM shares and likes were another aspect we wished to capture, it quickly became obvious that this was impossible due to the myriad SM paths some videos took after they became viral.

After selecting our examples, we went through each one and first determined open codes, then selective codes as we recognized repeating themes. This was an iterative process as similar codes were combined, and 
new codes discovered. The third step was the distillation of the selective codes into theoretical codes. Table 2 lists the cases.

Table 2. Examples of video activism

\begin{tabular}{|l|l|}
\hline Incident & Date \\
\hline Costco Mask Meltdown & $7 / 6 / 2020$ \\
\hline Vauhxx Booker & $7 / 4 / 2020$ \\
\hline Rayshard Brooks & $6 / 12 / 2020$ \\
\hline George Floyd & $5 / 26 / 2020$ \\
\hline Manuel Ellis & $3 / 3 / 2020$ \\
\hline Ahmaud Arbery & $2 / 23 / 2020$ \\
\hline Cédric Chouviat & $1 / 3 / 2020$ \\
\hline Willie Mccoy & $2 / 9 / 2019$ \\
\hline Nicholas Gibbs & $8 / 21 / 2018$ \\
\hline Philly Starbucks & $4 / 12 / 2018$ \\
\hline John Hernandez & $5 / 28 / 2017$ \\
\hline Keith Lamont Scott & $9 / 20 / 2016$ \\
\hline Philando Castile & $7 / 6 / 2016$ \\
\hline Alton Sterling & $7 / 5 / 2016$ \\
\hline Jeremy Mcdole & $9 / 23 / 2015$ \\
\hline Walter Scott & $4 / 4 / 2015$ \\
\hline Charley Leundeu Keunang & $3 / 1 / 2015$ \\
\hline 47 year old woman beaten & $12 / 31 / 2014$ \\
\hline Tamir Rice & $11 / 22 / 2014$ \\
\hline Eric Garner & $7 / 17 / 2014$ \\
\hline Mido Macia & $2 / 26 / 2013$ \\
\hline Kelly Thomas & $7 / 10 / 2011$ \\
\hline Neda Agha-Soltan & $6 / 20 / 2009$ \\
\hline Oscar Grant & $1 / 1 / 2009$ \\
\hline Robert Dziekański & $10 / 14 / 2007$ \\
\hline William Cardenas & $8 / 11 / 2006$ \\
\hline Otto Zehm & $3 / 18 / 2006$ \\
\hline Martin Anderson & $1 / 6 / 2006$ \\
\hline Solomos Solomou & $8 / 14 / 1996$ \\
\hline Tassos Isaac & $8 / 11 / 1996$ \\
\hline
\end{tabular}

\subsection{Analysis and Results}

The analysis of the 30 examples revealed 63 Open codes, 30 Selective codes, and 8 Theoretical codes. Table 3 lists the Selective and Theoretical codes.

Table 3. GTM codes

\begin{tabular}{|c|c|}
\hline Selective Code & Theoretical Code \\
\hline Instigation & \multirow{3}{*}{ Instigation } \\
\hline Racism & \\
\hline Self-righteousness & \\
\hline Group of victims & \multirow{2}{*}{ Target } \\
\hline Juvenile & \\
\hline Setting & Place \\
\hline Battery & \multirow{12}{*}{$\begin{array}{l}\text { Perceived } \\
\text { injustice }\end{array}$} \\
\hline Death & \\
\hline Excessive force & \\
\hline I can't breathe & \\
\hline Inaction & \\
\hline Police misreporting & \\
\hline Protocol not followed & \\
\hline Racism & \\
\hline Restraints & \\
\hline $\begin{array}{l}\text { Shot in the back or while } \\
\text { incapacitated }\end{array}$ & \\
\hline Threat to video maker & \\
\hline Victim family misreporting & \\
\hline Restraints & \multirow{2}{*}{ Tools } \\
\hline Weapon & \\
\hline Witnesses & Witness \\
\hline Potential evidence & \multirow{2}{*}{$\begin{array}{l}\text { Potential } \\
\text { evidence }\end{array}$} \\
\hline $\begin{array}{l}\text { Release of potential } \\
\text { evidence }\end{array}$ & \\
\hline \$ Settlement & \multirow{8}{*}{ Outcomes } \\
\hline Consequences & \\
\hline International conflict & \\
\hline No consequences & \\
\hline Police vindication & \\
\hline Protests & \\
\hline Riots & \\
\hline Social repercussions & \\
\hline
\end{tabular}


Instigation is defined as the incitement for perceived injustice. In most cases, the instigation was relatively minor or even legal, such as traffic stops or jogging, though some events started with suspects resisting arrest. We also noted that potential racism and selfrighteousness on the part of self-appointed accusers and vigilantes popped up frequently. These individuals took it upon themselves to either call police or directly intercede with the suspect or victim.

Targets are those that become the object of perceived injustice. We note that many of the incidents in our dataset include victims from disadvantaged groups and people of color. Even in the few cases where whites were assailed by police brutality, victim were homeless and/or suffered mental illness [11]. The targets ranged from individuals to small groups of victims, and several events had juveniles as their subject.

Place indicates the setting where events took place, and there was little consistency across cases. The locations ranged from drive-through fast-food restaurants to gas stations to organized protests. Residential neighborhoods and parks were not exempt.

Perceived injustice took many forms in the videos. Those codes that encompass physical harm include Battery, Death, Excessive force, I can't breathe, Restraints, and Shot in the back/while hurt. These codes represent how victims were injured, abused, and killed. An unfortunate number of cases saw victims harmed when incapacitated or in the act of running away and obviously causing no harm to aggressors. We also note the code "I can't breathe" is not only a nod to recent global protests in support of George Floyd, but also because our data set revealed that over half of the incidents involved asphyxiation, chokeholds, knee on the neck restraint, and the phrase "I can't breathe" was frequently heard in the videos of these events.

Other types of perceived injustice include Inaction, Police misreporting, Protocol not followed, Racism, Threat to video maker, and Victim family misreporting. Perceived injustice is not always caused by actions taken by aggressors. It may be the refusal to act, as potential evidenced in several videos showing police ignoring calls for help. Many videos potentially evidenced a lack of adherence to police protocols in terms of violent behavior towards suspects, although whether by ignorance or disregard is impossible to tell. Sometimes the video makers were threatened, and sometimes the families of victims pursued other agendas and misrepresented events.

Tools refer to the artifacts that aggressors use to enact perceived injustice and include the codes weapons and restraints. Both are a legitimate part of law enforcement, self-defense, and military action, however, their deployment in cases of perceived injustice often result in more serious outcomes.

Witness is a term that refers to those who see, document, or corroborate acts of perceived injustice, such as bystanders and others that capture perceived injustice on video. It is crucial to note that in most cases witnesses are accidental, although there are "cop watchers" that specifically follow police to document their actions [16]. We also note that many video witnesses are known to the victim (i.e., girlfriend, family, neighbor), suggesting that frequently victimized groups may be more prepared to serve as a witness and provide potential evidence.

Potential Evidence is the means of bringing aggressors to justice. We noted two variations: the video content, and the timing of video release. Several cases were found to have no investigation until videos were circulated and outrage built.

Outcomes of perceived injustice took many paths after exposure on social media. Some resulted in the prosecution of aggressors and monetary settlements counting into the millions for wrongful death. Others sparked protests and riots, not only locally but around the globe. A few incidents caused international conflict when a citizen of one country was abused in another country. Several events were notable because there was no consequence to the aggressors despite popular videos. Last, we noticed that potential video evidence is not always against the police or other elite groups. Two cases provided a video that exonerated police in the death of the suspect. 


\subsection{Discussion}

In Habermas' view, digital video that is spread on social media may exist as a response to community disruption from our modern life institutions and a call to open communications [21]. Such videos focus on uncovering perceived injustice, spreading unbiased information, and attempting to bring those responsible to legal justice. Because the videos are often live-streamed and amateur in nature, the truthfulness of the portrayal is often assumed without further evidence. These videos also become a shared form of communication in marginalized groups and beyond [17].

Looking at digital videos through a critical lens, we first examine the insights drawn from the data. We find that in most cases, potential video evidence generates sufficient outrage to influence investigations, which often (although not always) result in punitive outcomes for the aggressors or retribution to victims and their families. We also observed that many techniques used by aggressors for abuse were initially developed for restraint, not harm. However, in many of the examples, these supposedly non-lethal procedures were amplified to the point of permanent damage and death. Our last insight comes from the observation that many bystander videos are taken and uploaded to SM platforms within minutes or even seconds of an event unfolding. $27 \%$ of smartphone users take photos or videos daily [10]. Yet, the volume of these videos indicates that there may be higher sensitivity in marginalized communities as to the value of evidentiary video on social media. This sensitivity may lead community members to be more prepared to use their smartphone or other devices for quick recording and dissemination.

Next, we suggest a critique of the institutions that enable the types of perceived societal injustice captured on these videos. Governments and law enforcement are servants of the people, yet that message appears lost on some in these offices. We suggest that the frequency and virality of potential video evidence is a strong incentive for just behavior to those who abuse their office. We also observed that several cases resulted in devastating outcomes because of aggressors sidestepping protocols. While this paper is not a deep dive into the problems of modern policing, it does appear from our limited data set that lack of training, lack of adherence to procedure, and little enforcement of rules exacerbates the situation and drag good cops down with the bad ones.

Last, we look at transformative redefinition to recommend solutions. We propose that digital video capture of perceived injustice and social media dissemination is an emancipatory communicative act [2]. As such, tools to aid the process would be useful. There are a multitude of existing video apps. However, apps that could simultaneously live stream and notify benevolent institutions might help reduce harm by drawing the attention of senior officials or the press early on. We also suggest that frequent hands-on training for quick video creation and transmission could be offered at community centers in districts often hurt by perceived injustices.

Along with technical training, participants should learn about the ethics of their actions and reiterate their dedication to honesty. If evidentiary videos lose their authenticity and perceived trustworthiness, they will have little value for society. Last, those aggressors who cause perceived injustice need to understand the growth of video activism and its current power and influence. While aggressors are unlikely to turn sympathetic, they may perceive it wiser to save themselves from excoriation, prison, job loss, civil suits, or other negative consequences considering the new technologies that document their actions.

Another aspect of these digital videos is how they provide an easily identifiable frame, which aids in dissemination and persuasiveness [43]. As it becomes more common, viewers can quickly determine that they will be seeing an incident of perceived social injustice, usually involving those in power (such as police) or those who think they have power (such as self-appointed accusers and vigilantes). Such recognition afforded by frames speeds up a viewer's response [43].

On the other hand, the frequency of these videos may cause desensitization and 
normalization of deviance over time [41], which could lead to a U-shaped curve of video efficacy. First, the efficacy of videos is low because of limited spread. As they become more frequent and result in positive outcomes, their influence grows through social media and virality, reaching new audiences and popularity. Over time, however, continued high levels of new video may cause desensitization which reduces the efficacy of evidentiary videos.

Last, the videos (regardless of frequency) may never influence a portion of the population because some people will not believe in the legitimacy of the images. Such people may find the behavior in the videos to be so abhorrent that they cannot think it is true. They may also be skeptical because the source does not align with their worldview, exhibiting cognitive bias [4]. Those with very strong negative views about the videos may consider them deepfakes and seek to discredit them.

We draw several implications from this exploratory study. First, bystander video can be an effective means to document perceived injustice by providing potential visual evidence that can be quickly recorded and disseminated. These actions can speed up public response which in turn speeds up institutional response. Video activism can be particularly helpful to marginalized people who often lack a voice because it does not rely on campaigns, advertising, or fundraising to arouse supporters and force action by elites. However, as popular as it is today, it may not be a long-term solution if people become desensitized to the videos. Additionally, the videos may be subverted to dissuade people or may be found to provide revenue generation from ads, much like fake news $[1,6]$.

\subsection{Conclusion}

This study asks How do bystander digital videos that are spread through social media impact perceived social injustice? What are the elements that make up this phenomenon?

We answer in several ways. First, by providing frames, the videos are quickly recognized and disseminated, which rouses communities. The aroused communities may be incited to protest and riot, and the message may spread beyond the community and transcend national borders. Such social wildfires are influential in forcing elites to act against aggressors and serve justice to victims and their families.

Second, the videos provide potential evidence of perceived injustice that can be used in court. This provides a basis for retribution and settlements for victims and their families. It also provides a basis for firing, fining, or incarcerating aggressors. These applications show how the videos might serve as inhibitors of perceived injustice if they were publicized as such.

We break down the phenomenon into eight areas: Instigation, Target, Place, Perceived injustice, Tools, Witness, Potential evidence, and Outcomes. This dissection allows us to see how events of perceived injustice are started and how they end, who is victimized and how, and the means of uncovering and communicating the perceived injustice.

This study contributes to the literature on digital activism and video activism with a critical theory view and a grounded theory analysis, which have not been commonly used in researching this particular phenomenon. We also recognize several limitations in the current study. First, our data set was limited to 30 incidents. While they were chosen randomly, incidents with higher placement on search pages likely introduced bias into the data selection.

Future research on this topic could follow several paths. Experiments that show these videos to participants under different circumstances might reveal insights, as might surveys or witness interviews. We caution potential researchers that the subject videos are often hard to watch. Additionally, they engender empathetic responses in the researchers, which may create possible bias.

To conclude, video activism and its use as an emancipatory technology is expanding, driven by viral social media, punishments of aggressors, and retribution to victims. Some day, society will find new and more effective methods to document perceived injustice. But for now, bystander digital videos have become a staple emancipatory technology in restoring justice. 


\subsection{References}

[1] Allcott, H., and M. Gentzkow, "Social Media and Fake News in the 2016 Election", Journal of Economic Perspectives 31(2), 2017, pp. 211-236.

[2] Alvesson, M., and S. Deetz, Doing Critical Management Research, SAGE, 2000.

[3] Andrade, A.D., and C. Urquhart, "Unveiling the modernity bias: a critical examination of the politics of ICT4D", Information Technology for Development 18(4), 2012, pp. 281-292.

[4] Arceneaux, K., "Cognitive Biases and the Strength of Political Arguments", American Journal of Political Science 56(2), 2012, pp. 271-285.

[5] Askanius, T., "DIY Dying: Video Activism as Archive, Commemoration and Potential evidence", International Journal of E-Politics 3(1), 2012, pp. 1225.

[6] Baum, K., S. MeiÃŁner, O. Abramova, and H. Krasnova, "Do They Really Care About Targeted Political Ads? Investigation of User Privacy Concerns And Preferences", ECIS 2019 Proceedings, (2019), 18.

[7] Baum, M.A., and P. Gussin, "In the Eye of the Beholder: How Information Shortcuts Shape Individual Perceptions of Bias in the Media", Quarterly Journal of Political Science 3(1), 2008, pp. $1-31$.

[8] Bourdieu, P., Outline of a Theory of Practice, Cambridge University Press, 1977.

[9] Bourdieu, P., The Logic of Practice, Stanford University Press, 1990.

[10] Clement, J., "Top U.S. smartphone activities 2018”, Statista, 2018. https://www.statista.com/statistics/187128/leadingus-smartphone-activities/

[11] Conder, C., Ex-cops charged in beating death of Kelly Thomas found not guilty, CNN, 2012.

[12] Doucett, G., and J. Miller, "GeorgeFloyd Protest - police brutality videos on Twitter - Google Drive", 2020.

https://docs.google.com/spreadsheets/u/1/d/1YmZeS xpz52qT-
10tkCjWOwOGkQqle7Wd1P7ZM1wMW0E/htmlvie w?pru=AAABcq16DI8*mIHYeMnoj9XWUp3Svb_K ZA\#

[13] Foucault, M., "The Subject and Power", Critical Inquiry 8(4), 1982, pp. 777-795.

[14] Fox, R.L., R.W. Van Sickel, and T.L. Steiger, Tabloid justice: criminal justice in an age of media frenzy, Lynne Rienner Publishers, Boulder, 2007.

[15] Garrett, R.K., "Protest in an Information Society: a review of literature on social movements and new ICTs", Information, Communication \& Society 9(2), 2006, pp. 202-224.

[16] Garver, R., "Amateur Videos Are Increasingly Forcing US Police Accountability", Voice of America, 2020. https://www.voanews.com/usa/amateur-videosare-increasingly-forcing-us-police-accountability

[17] Gaspar, C.M., "Habermas' Theory of Communicative Action", Philippine Studies 47(3), 1999, pp. 407-425.

[18] George, J., J. (Kevin) Yan, and D.E. Leidner, "Data Philanthropy: Corporate Responsibility with Strategic Value?", Information Systems Management 37(2), 2020, pp. 30.

[19] George, J.J., and D.E. Leidner, "From clicktivism to hacktivism: Understanding digital activism", Information and Organization, 2019.

[20] Gregory, S., "Cameras Everywhere: Ubiquitous Video Documentation of Human Rights, New Forms of Video Advocacy, and Considerations of Safety, Security, Dignity and Consent", Journal of Human Rights Practice 2(2), 2010, pp. 191-207.

[21] Habermas, J., The theory of communicative action, Beacon Press, Boston, 1984.

[22] Hermida, A., and V. Hernández-Santaolalla, "Twitter and video activism as tools for countersurveillance: the case of social protests in Spain", Information, Communication \& Society 21(3), 2018, pp. $416-433$.

[23] Hirschheim, R., and H.K. Klein, "Realizing Emancipatory Principles in Information Systems Development: The Case for ETHICS", MIS Quarterly 18(1), 1994, pp. 83-109. 
[24] Jones, K.A., W.E. Crozier, and D. Strange, “Look there! The effect of perspective, attention, and instructions on how people understand recorded police encounters", Behavioral Sciences \& the Law 37(6), 2019, pp. 711-731.

[25] Joseph, K.J., Growth of ICT and ICT for development: Realities of the myths of the Indian experience, World Institute for Development Economics Research, 2002.

[26] Kanungo, S., "On the emancipatory role of rural information systems", Information Technology \& People 17(4), 2004, pp. 407-422.

[27] Klein, H.K., and M.D. Myers, “A set of principles for conducting and evaluating interpretive field studies in information systems", MIS Quarterly 23(1), 1999, pp. 67-93.

[28] Lleras, E., "Is it possible to develop an emancipatory approach to technology?", Systems Practice 9(4), 1996, pp. 333-338.

[29] Miranda, S.M., A. Young, and E. Yetgin, “Are social media emancipatory or hegemonic? Societal effects of mass media digitization", MIS Quarterly 40(2), 2016, pp. 303-329.

[30] Moore, D., and R. Singh, "Seeing crime, feeling crime: Visual potential evidence, emotions, and the prosecution of domestic violence", Theoretical Criminology 22(1), 2018, pp. 116-132.

[31] Moravec, P., R. Minas, and A.R. Dennis, "Fake News on Social Media: People Believe What They Want to Believe When it Makes No Sense at All', MIS Quarterly 43(4), 2019, pp. 1343-1360.

[32] Mowatt, R.A., "Black Lives as Snuff: The Silent Complicity in Viewing Black Death", Biography 41(4), 2018, pp. 777-806.

[33] Murungi, D., D. Yates, S. Purao, J. Yu, and R. Zhan, "Factual or Believable? Negotiating the Boundaries of Confirmation Bias in Online News Stories", (2019), 10.

[34] Myers, M.D., and H.K. Klein, "A Set of Principles for Conducting Critical Research in Information Systems", MIS Quarterly 35(1), 2011, pp. 17-36.
[35] Newell, B.C., "Context, visibility, and control: Police work and the contested objectivity of bystander video", New Media \& Society 21(1), 2019, pp. 60-76.

[36] Njilo, N., "Police killed him five years ago now Mido Macia's family gets paid out", Times LIVE, 2018 . https://www.timeslive.co.za/news/southafrica/2018-11-21-police-killed-him-five-years-ago-now-mido-macias-family-gets-paid-out/

[37] Ray, A., and J. George, “Online Disinformation and the Psychological Bases of Prejudice and Political Conservatism", Proceedings of the 52nd Hawaii International Conference on System Sciences|2019, (2019), 11.

[38] The Associated Press, "Bystander video leading to more arrests of abusive police", Associated Press, 2020.

https://bangordailynews.com/2020/06/15/news/bysta nder-video-leading-to-more-arrests-of-abusivepolice/

[39] Westerlund, M., "The Emergence of Deepfake Technology: A Review", Technology Innovation Management Review 9(11), 2019, pp. 40-53.

[40] Wiesche, M., M.C. Jurisch, P.W. Yetton, and H. Krcmar, "Grounded Theory Methodology in Information Systems Research”, MIS Quarterly 41(3), 2017, pp. 685-701.

[41] Williams, S.N., and A.V. Clarke, "How the Desensitization of Police Violence, Stereotyped Language, and Racial Bias Impact Black Communities", Psychology and Cognitive Sciences Open Journal 5(2), 2019, pp. 62-67.

[42] Wilson, D.J., and T. Serisier, "Video Activism and the ambiguities of counter-surveillance", Surveillance \& Society 8(2), 2010, pp. 166-180.

[43] Yetgin, E., A.G. Young, and S.M. Miranda, "Cultural production of protest frames and tactics: Cybermediaries and the SOPA movement", Proceedings of the 33rd International Conference on Information Systems, (2012).

[44] Young, A.G., "Using ICT for social good: Cultural identity restoration through emancipatory pedagogy", Information Systems Journal 28(2), 2017, pp. $340-358$.

[45] "Synthesia - AI video generation platform", 2020. https://www.synthesia.io/ 